\title{
Role of Transcranial Doppler in Cardiac Surgery Patients
}

\author{
Pranav Gupta ${ }^{1} \cdot$ Luzius A. Steiner $^{1}$ \\ Accepted: 5 August 2021 / Published online: 18 October 2021 \\ (c) The Author(s) 2021
}

\begin{abstract}
Purpose of Review This review discusses applications of transcranial Doppler (TCD) in cardiac surgery, its efficacy in preventing adverse events such as postoperative cognitive decline and stroke, and its impact on clinical outcomes in these patients.

Recent Findings TCD alone and in combination with other neuromonitoring modalities has attracted attention as a potential monitoring tool in cardiac surgery patients. TCD allows not only the detection of microemboli and measurement of cerebral blood flow velocity in cerebral arteries but also the assessment of cerebral autoregulation.

Summary Neuromonitoring is critically important in cardiac surgery as surgical and anesthetic interventions as well as several other factors may increase the risk of cerebral embolization (gaseous and particulate) and cerebral perfusion anomalies, which may lead to adverse neurological events. As an experimental tool, TCD has revealed a possible association of poor neurological outcome with intraoperative cerebral emboli and impaired cerebral perfusion. However, to date, there is no evidence that routine use of transcranial Doppler can improve neurological outcome after cardiac surgery.
\end{abstract}

Keywords Transcranial Doppler $\cdot$ Neuromonitoring $\cdot$ Cerebral emboli $\cdot$ Cerebral blood flow $\cdot$ Postoperative cognitive decline $\cdot$ Poor neurological outcome $\cdot$ Cardiac surgery

\section{Introduction}

Neurologic complications are common in cardiac surgery (CS) patients, with temporary neurologic dysfunction occurring in $8.0 \%$ to $10.3 \%$ and permanent neurologic dysfunction occurring in another $7.3 \%$ to $12.8 \%$ [1]. Poor neurological outcome in CS patients depends upon several factors, such as preexisting intra- and extracranial atherosclerosis with impaired autoregulation and intracranial reserve, discordant cooling and warming of cerebral tissue, grave incidents causing circulatory crisis, such as massive embolism, hemorrhage, cardiac arrest, and cerebral venous hypertension [2, 3]. Presumably, deranged cerebral perfusion, due to cerebral embolization and reduced cerebral blood flow (CBF), is one of the important factors. As a few recent publications have

This article is part of the Topical Collection on Cardiovascular Anesthesia

Luzius A. Steiner

luzius.steiner@usb.ch

1 Clinic for Anaesthesia, Intermediate Care, Prehospital Emergency Medicine and Pain Therapy, University Hospital Basel, Spitalstrasse 21, 4031 Basel, Switzerland suggested that embolism and cerebral hypoperfusion are probably the reasons for perioperative brain injury in CS patients [2], the impact of embolization and hypoperfusion on the brain is becoming a growing concern. Thus, there is a clear need to identify and develop neuromonitoring modalities to allow for reliable detection of these conditions and to provide actionable insights to improve patient outcome.

Transcranial Doppler (TCD) ultrasound is a non-invasive and compact tool for measuring cerebral hemodynamic changes. High-intensity transient signals (HITS) are thought to represent particulate or gaseous microembolic particles $[4,5]$, which can be measured intraoperatively using TCD. It may be useful in verifying blood flow across both cerebral hemispheres in patients undergoing antegrade cerebral perfusion during surgery on the aortic arch. TCD could be useful in tracking cerebral autoregulation during surgery, allowing for more personalized blood pressure goals $[6,7]$.

\section{Technique}

TCD, which has been used in clinical practice for around 40 years [8], uses a spectral display and established criteria, such as analysis of wave-signal pattern, arterial depth, and 


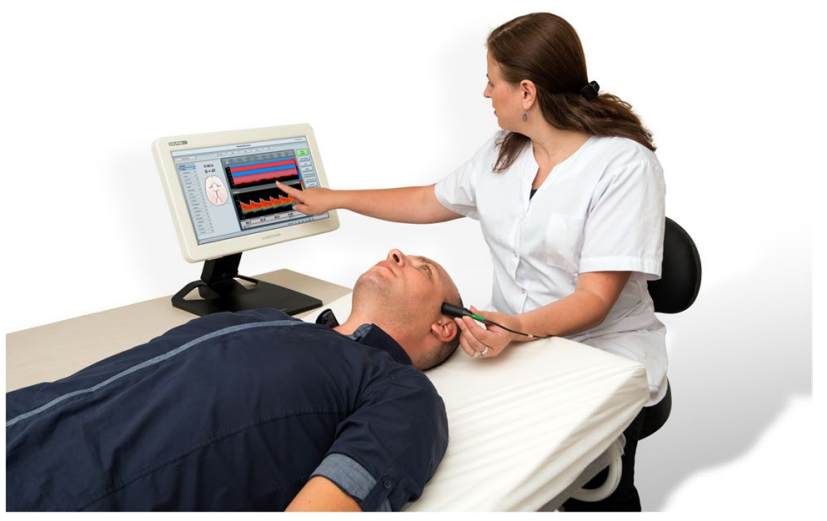

Fig. 1 TCD system (Dolphin/MAX). Reproduced with permission from Viasonix

direction of arterial blood flow to identify the cerebral arteries. It is a valuable tool for multimodal brain monitoring and evaluation of essential parameters such as cerebral autoregulation, critical closure pressure, and cerebral compliance, as it permits evaluation and close monitoring of CBF velocity [9-11] as well as assessment of cerebrovascular reactivity. Newer equipment also allows visualization of intracerebral blood vessels. However, to the best of our knowledge, this technology is not widely used in the intraoperative setting and will not be covered in this review.

The TCD probe is usually placed over the temporal area, due to the thinness of the bone, which serves as a suitable "window" to transmit ultrasound beam intracranially (Fig. 1). The beam is reflected back to the probe by red blood cells circulating in the blood vessels. The resultant Doppler effect causes a shift in frequency corresponding to the blood flow velocity in that particular vessel. The intracranial arteries such as middle (MCA), anterior (ACA), and posterior (PCA) cerebral arteries can be monitored through temporal region. The MCA is ideal for TCD monitoring owing to its direct path to the Doppler probe, and it remains the only intracranial vessel used for intraoperative continuous Doppler monitoring.

To identify cerebral emboli, most TCD devices use pulsed-wave ultrasonography and monitor the backscatter from the emboli. Microemboli cause short intermittent amplifications in the ultrasound signal that are registered as HITS [12••] (Fig. 2 [13]). TCD may, thus, serve as a promising tool to effectively monitor $\mathrm{CBF}$ and cerebral embolic events in CS patients.

In this narrative review, we focus on the use of transcranial Doppler in adult patients undergoing CS. This review is based on the literature published over the last twenty years.

\section{Methods}

The electronic database of the National Library of Medicine (Pubmed.gov) was searched from January 2000 until February 2021 using the search terms "cardiac surgery" and "transcranial Doppler" to identify suitable articles. This yielded 160 articles, of which 23 matched our selection criteria. Articles were included if they investigated or demonstrated the use of TCD to detect cerebral emboli and/or measure $\mathrm{CBF}$ velocity as well as their effect on neurophysiological outcome in adult CS patients.
Fig. 2 Transcranial Doppler recordings of the left middle cerebral artery show embolic signals. The high-intensity transient signals (HITS) seen with emboli are indicated by arrows [13]. Reproduced with permission from Thieme
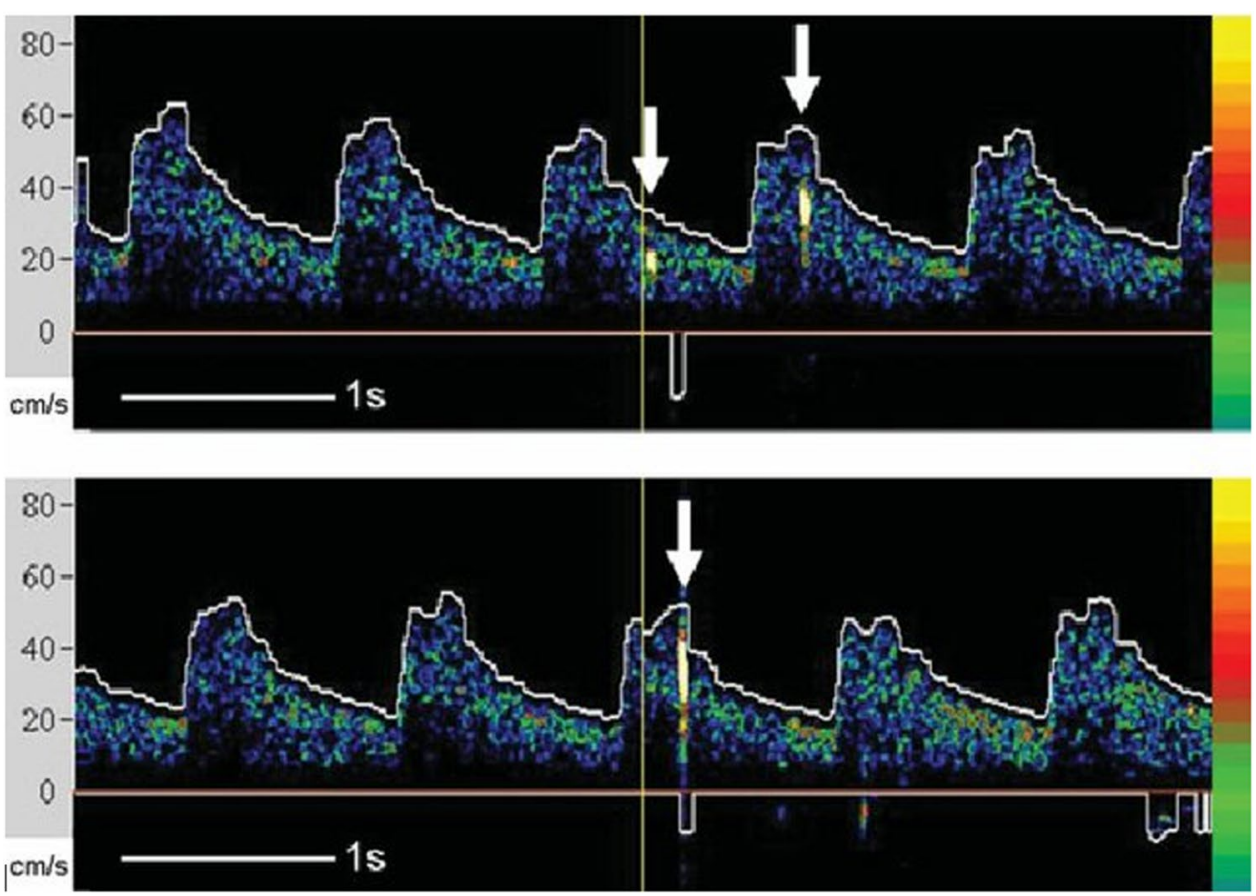
The resulting literature was divided into two groups: one focusing on emboli the other on CBF. Fourteen articles were allocated to the emboli group and ten to the $\mathrm{CBF}$ group. However, the number of original articles was low, including only two in each group. Two review articles from Razumovsky et al. [14] and Saidi et al. [15] were included in both groups.

\section{Cerebral Emboli}

Microemboli entering the cerebral circulation appear to be one of the common causes of stroke or neurological complications during CABG surgery [16-22]. Emboli can be qualitatively classified into solid and gaseous forms, and many potential sources of solid emboli have been recognized [23]. If an atheroma is dislodged during aortic manipulation, massive and severe solid emboli can result [24, 25]. Smaller particulate emboli can be caused by silicone or polyvinyl chloride discharged from cardiopulmonary bypass (CPB) circuit tubing [26], platelet-fibrin aggregates [27], and fat and cotton fibers in the surgical field [28]. Interestingly, thousands of tiny lipid emboli were discovered in the brain microcirculation following CPB [29].

Larger solid emboli $(>200 \mu)$ obstruct larger arteries supplying regional vascular zones, resulting in a neurological symptoms or even stroke. Smaller solid emboli may only obstruct smaller arteries and arterioles that lead to oligosymptomatic to asymptomatic disease with no manifestation of physiologic deficits [30 $30^{\circ}$. There is also substantial evidence of a link between mobile atheromatous plaques and postoperative stroke [24, 25].

Bubble oxygenators, the venous blood reservoir, air in the $\mathrm{CPB}$ venous line, poor surgical de-airing in open chamber procedures, introduction via perfusionist interventions, and entrainment of air into cardiotomy suction blood are all possible sources of gaseous microemboli. Artificial heart valves and decompression illness are two possible endogenous causes of gaseous emboli [23].

Microbubbles circulating in the bloodstream can obstruct blood flow in the capillary beds of numerous organs, leading to tissue ischemia. A multitude of inflammatory responses such as thrombocyte activation, stimulation of clotting pathways, and complement pathway activation [31] are triggered following tissue ischemia and cause further microcirculation obstruction and tissue damage [32].

Multiple experimental studies have demonstrated that the circulating microbubbles can be detrimental [23]. Bubbles, especially microbubbles circulating in cerebral vessels ranging from 10 to $20 \mu \mathrm{m}(\mathrm{SD})$ may disrupt the blood-brain barrier [2,33-35]. Use of CPB promotes the introduction of such microbubbles into the circulation [36].
Utilizing a gas filter during CABG surgery has shown a trend toward improved neurological outcome after surgery [37]. Multiple studies [38-41] vouch for the value of TCD in identifying misplacement of selective cerebral perfusion cannulas.

Despite abundant literature describing possible sources and pathogenicity associated with cerebral emboli, significant evidence to prove an association to POCD in CS patients is lacking. To investigate this further, we retrieved 14 short-listed articles on this topic including 12 reviews $[14,15,30,42-50]$, one observational study $\left[51^{\circ}\right]$, and one prospective study $\left[52^{\bullet}\right]$.

The prospective study by Abu-Omar et al. [52 ${ }^{\bullet}$ ] from 2004, compared the number and nature (i.e., solid or gaseous) of microemboli in patients treated with on-pump and off-pump CS using multifrequency TCD monitoring of the MCA in a cohort of 45 patients (15 off-pump CABG, 15 on-pump CABG, and 15 open cardiac procedures). Microemboli were shown to be 7 times higher in patients undergoing on-pump CABG compared to those undergoing offpump $\mathrm{CABG}$, while patients undergoing open procedures demonstrated a 22-fold increase. However, Abu-Omar et al. did not measure any clinical outcomes in the investigated patients. Furthermore, the fraction of solid microemboli in the off-pump group was similarly much lower. The authors concluded that cerebral microembolization is significantly reduced by avoiding CPB.

Most microemboli occuring during CS are gaseous, with on-pump procedures having a higher frequency of solid microemboli. This could explain why individuals receiving off-pump vs. on-pump surgeries experience less neuropsychological impairment $[53,54]$. Interestingly, two other RCTs, both by Van Dijk D et al., only partially support the above findings. They show that patients who underwent CABG surgery without CPB (off-pump) had better cognitive outcomes three months after the treatment, although the effects were minor and evened out after one year [55]. Avoiding CPB for CABG in low-risk patients also had no influence on cognitive outcomes after 5 years [56].

Based on previous studies, Rodriguez et al. [51 $\left.{ }^{\circ}\right]$ presume that neurologic outcome is minimally affected by gaseous emboli [57], although particulate macro- and microemboli are thought to be linked to stroke and cognitive impairment [54]. The authors performed an observational study with the objective of finding a method to differentiate among presumably benign gaseous bubbles and allegedly more harmful particulate emboli.

Most embolic signals in mechanical heart valve patients are related to gaseous microbubbles, which occur due to a phenomena known as cavitation (i.e., rapid change of pressure in surrounding fluid) [58,59], but solid microemboli may also constitute an unknown fraction. 
Bio-prosthetic cardiac valves, on the other hand, do not exhibit cavitation. The embolic signals detected in individuals with bio-prosthetic heart valves are thought to consitute solid rather than gaseous emboli. [58, 60, 61].

When compared to room air, giving mechanical heart valve patients $100 \%$ oxygen during transcranial Doppler evaluation reduced the number of embolic signals. At two Doppler tests, 4 hours and 4 days after surgery, 17 mechanical heart valve patients show embolic signals in room air $(n=141)$ and with $100 \%$ oxygen $(n=45)$. While in seven patients with bio-prosthetic valves inhaling $100 \%$ oxygen, solid embolic signals $(n=31)$ were detected within the first $4 \mathrm{~h}$ following surgery. The relative intensities of embolic signals in mechanical heart valve patients inhaling $100 \%$ oxygen were lower than in patients breathing room air. During provision of $100 \%$ oxygen, the signal-relative intensity distribution across mechanical and bio-prosthetic valve groups was alike $\left[51^{\circ}\right]$.

According to Rodriguez et al., the majority of brain emboli revealed by TCD while inhaling $100 \%$ oxygen in MHV patients are non-gaseous. The highest precision for distinguishing non-gaseous from gaseous emboli was attained using a 16-dB cut-off threshold (sensitivity: $60 \%$; specificity: 82\%; area: 0.721; $P<0.0001)$ [51•].

All 14 articles concur that TCD can detect gaseous and particulate microembolic signals (i.e., HITS) in the cerebral circulation in the patients undergoing CS provided the insonation window is available and experienced personnel perform the investigation. However, despite considerable advancements in Doppler technology, reliable discrimination of solid versus gaseous microemboli and artifacts could thus far not be achieved.

In addition, the retrieved literature disagrees on the adverse effects of microemboli in general on cognitive function. As we used a 20-year cutoff for the literature included in this review, data prior to the cutoff are only presented in reviews published within the last 20 years. Seven [30, 45-50] of the 12 reviews suggested insufficient evidence to prove the correlation between microembolic events and neurological damage and/or poor neurological outcome. Nevertheless, four reviews [14, 15, 43, 44], one observational study [51•] and one prospective study [52], suggested a possible association between the two. Another review found an indirect link between gaseous microemboli and poor neurological outcomes [42].

Furthermore, among the studies that agree on an association between cerebral microemboli and poor neurological outcome, there is a further disagreement over the pathogenicity of gaseous and solid microemboli.

\section{Cerebral Blood Flow}

POCD is very common in patients undergoing heart surgery. The severity of CNS injury varies, extending from modest personality, behavioral, and cognitive problems to serious neurological impairment (i.e., stroke). A prospective study found that c.a. $6 \%$ of patients had unfavorable cerebral outcomes (stroke) [12••]. At 5 years following CS, $42 \%$ of patients showed neuropsychologic dysfunction in another study [62]. In few studies, complications following CS (cardiac, neurologic, pulmonary, and acute renal failure) have been reported in a range varying from $24 \%$ to $69 \%$ [63, 64]. Nevertheless, it is clear that the main cause of neurological complications in CS patients is larger cerebral emboli. It is also clear that changes in cerebral perfusion pressure and blood flow can significantly affect the extent of injury following an embolic insult [15]. Therefore, maintaining optimum cerebral perfusion during $\mathrm{CPB}$ and circulatory arrest may be a crucial aspect of intraoperative care during CS [65].

TCD can be used to measure CBF velocities (mean, systolic, and diastolic) in the insonated vessel by monitoring the change in frequency in the reflected sound $[7,15]$. In addition, the direction of CBF is of utmost importance during hypothermic circulatory arrest using selective cerebral perfusion. In various clinical scenarios such as cannu la mal-positioning or aortic dissection, timely detection of abrupt decreases in CBF may allow prompt corrective interventions to prevent cerebral insult. In patients undergoing carotid artery endartectomy, the threshold decline in CBF velocity for identifying cerebral ischemia was investigated. Moritz et al. reported that a 50\% reduction in MCA blood flow velocity has a $100 \%$ sensitivity and $86 \%$ specificity for identifying ischemia in these patients [66]. However, to the best of our knowledge, no comparable data are available for CS.

CBF autoregulation can be tracked and recorded by analyzing the patient's transcranial Doppler and arterial blood pressure signals [67-69]. The signals are screened to concentrate on low-frequency vasomotor activity that promotes autoregulatory vascular alterations $(0.2 \mathrm{~s}$ to $2 \mathrm{~min})$. The correlation coefficient between cerebral perfusion pressure or mean arterial pressure and TCD-estimated CBF velocity can be determined, resulting in the variable mean velocity index (Mx). There is no link between CBF velocity and mean arterial pressure when autoregulation is adequate, but when mean arterial pressure exceeds the autoregulation limits, $\mathrm{Mx}$ reaches 1 , indicating that flow is pressure-dependent. Other methods have also been used. Thus, in theory, a personalized MAP target based on autoregulation may improve postoperative neurological outcome.

As described previously, ten articles were allocated to CBF group including eight reviews [3, 7, 14, 15, 65, 70-72], 
one case report [40], and one prospective study [73]. All ten articles stated that TCD could be used to measure CBF velocity, and autoregulatory parameters can be further derived from this resultant data. However, there is no consensus on the efficacy TCD or on the impact of the obtained data on the clinical outcome.

One case report [40] and one review [3] suggest that routine use of TCD to detect silent cerebral ischemia and to assess cerebral autoregulation will have significant clinical impact.

In their case report on surgical treatment of aortic dissection Stanford type-A, Ghazy et al. used TCD to analyze and improve CBF [40]. Antegrade selective cerebral perfusion was established under moderate hypothermic circulatory arrest, and emergency surgery using a Bentall procedure was conducted. After lowering the patient's core temperature to $28{ }^{\circ} \mathrm{C}$, the flow in $\mathrm{CPB}$ was reduced to $1.5 \mathrm{l} / \mathrm{min}$, and the supra-aortic arteries were occluded, signaling the start of selective cerebral perfusion under continuous TCD monitoring.

The circle of Willis as well as the presence of sufficient communicator vessels was visualized satisfactorily. TCD revealed adequate antegrade flow in the right hemisphere perfusion. Despite preoperative TCD sonography confirmation of sufficiency, the cross-filling over the communicators to the left MCA was absent. Following this observation, $\mathrm{CPB}$ flow was increased to $2.0 \mathrm{l} / \mathrm{min}$ and $\mathrm{PaCO} 2$ was increased to $45 \mathrm{mmHg}$ in order to generate cerebral vasodilation. This measure resulted in the communicators reopening and the left MCA receiving appropriate cross-filling and perfusion. The procedure was eventless subsequently.

According to the authors, TCD allows for real-time observation of cerebral perfusion over the circle of Willis. In this scenario, the surgical team was able to optimize antegrade cerebral perfusion thanks to continuous real-time input. Monitoring cerebral vasoreactivity and increasing $\mathrm{PCO} 2$ and CPB flow with subsequent reopening of the cerebral communicators allowed for adequate perfusion of both hemispheres. Two reviews $[3,14]$ suggest that TCD appears to be an effective neuromonitoring tool for improving neurological outcome. Two further reviews $[7,72]$ suggest that perioperative TCD monitoring during cardiovascular surgery could identify thromboembolism and perfusion disorders as the foremost reasons for perioperative neurological complications and strokes. The quality of evidence and the strength of the recommendations, however, are class III and type $\mathrm{C}$, respectively.

One review [70] and one prospective study (described below) indirectly support the efficacy of TCD in measuring and $\mathrm{CBF}$ velocity.

In a group of 24 patients, Baufreton et al. [73] looked at the effect of heparin-coated extracorporeal CPB circuits on complement activation and CBF velocity. TCD was performed on the MCA (before and after CPB) to evaluate systolic, diastolic, and mean $\mathrm{CBF}$ velocities. In addition, the terminal complement complex (sC5b-9) was quantified as a marker of complement activation [7, 15].

The authors were able to demonstrate a correlation between increased CBF velocity after CPB as well as reduced complement activation in patients who underwent heparin-coated CPB compared to control patients in the noncoated CPB group.

Although the efficacy of TCD as a neuromonitoring tool in CS patients has yet to be established, two reviews suggest that the quality of the images acquired through a narrow and at times absent Doppler window and expertise of a sufficiently experienced investigator are crucial for accuracy of TCD findings. [65, 71].

Hogue et al. [74••] concluded in a recent randomized controlled trial that during $\mathrm{CPB}$, cerebral autoregulation monitoring based on mean arterial pressure did not decrease the prevalence of stroke or delayed neurological recovery in high-risk patients compared to usual care, although it was associated with less delirium and better performance on memory tests 4 to 6 weeks after surgery. This shows that TCD could be effective in monitoring cerebral autoregulation during surgery, allowing for more personalized blood pressure objectives $[6,7]$.

\section{Discussion}

TCD has several strengths in being non-invasive and being able to detect cerebral emboli and to confirm bi-hemispheric flow during CPB. It could also help to determine personalized autoregulation and blood pressure thresholds. Nevertheless, TCD necessitates specific monitoring and experience. It can also be challenging to identify the "window" required for insonation in all patients. In addition, continuous monitoring is technically demanding due to the risk of dislocating the probes (e.g., due to manipulation of the probe or manipulation of other monitoring equipment such as the transesophageal echocardiography probe).

Given the likelihood of gaseous and solid embolisms, the utility of routine TCD monitoring to detect acute cerebral ischemia during CS has been investigated [4, 75]. TCD is the only imaging technique that can identify both gaseous and particulate cerebral emboli [76, 77]. However, its value to improve neurological outcomes has not been shown.

In addition to $\mathrm{CS}$, which includes interventional valve replacement, surgeries and interventions on the carotid artery put the brain at risk. TCD can identify ipsilateral stroke caused by the dislodging of arterial plaques [76]. Furthermore, CBF velocity can be determined while the 
carotid artery is clamped for endarterectomy (CEA). TCD readings in combination with EEG have been suggested to detect silent cerebral ischemia during this surgery and as an indication for shunt implantation [27, 31, 34]. After CEA surgery, about 1 in every 10 patients suffer cerebral hyper-perfusion syndrome, which can lead to intracerebral hemorrhage. TCD can be used to detect and monitor this condition. [34]. For these reasons, transcranial Doppler is classified as a class III indication for monitoring cerebral embolization or hypoperfusion in the current American Society of Neuroimaging recommendations on neuromonitoring during CS (quality of evidence: class III; strength of recommendation: type C) [72].

\section{Conclusion}

Intraoperative neuromonitoring would be of prime importance in CS where surgical and anesthetic interventions may increase the risk of cerebral perfusion anomalies and cerebral embolization (gaseous and particulate), which may lead to poor neurological outcomes. TCD monitoring appears to be valuable in the assessment and refinement of established and more recent surgical techniques as well as in the development of new techniques and instrumentation [15]. However, it does not seem to be the ideal tool for routine clinical use due to the need for a skilled TCD operator for reliable measurements, the challenges accompanying continuous monitoring, and the availability of an insonation window. Nevertheless, TCD can be used to monitor CBF velocity and derived parameters in patients undergoing cardiac surgeries, although it may not effectively quantify all emboli or differentiate between gaseous and particulate matter embolus.

As an experimental tool, TCD has revealed a possible association of poor neurological outcome with intraoperative cerebral emboli and impaired cerebral perfusion. To date, there is no evidence that the routine use of transcranial Doppler can improve clinical outcomes after CS, and its use remains largely experimental.

Funding Open access funding provided by University of Basel.

\section{Declarations}

Conflict of Interest The authors do not have any potential conflicts of interest to disclose.

Open Access This article is licensed under a Creative Commons Attribution 4.0 International License, which permits use, sharing, adaptation, distribution and reproduction in any medium or format, as long as you give appropriate credit to the original author(s) and the source, provide a link to the Creative Commons licence, and indicate if changes were made. The images or other third party material in this article are included in the article's Creative Commons licence, unless indicated otherwise in a credit line to the material. If material is not included in the article's Creative Commons licence and your intended use is not permitted by statutory regulation or exceeds the permitted use, you will need to obtain permission directly from the copyright holder. To view a copy of this licence, visit http://creativecommons.org/licenses/by/4.0/.

\section{References}

Papers of particular interest, published recently, have been highlighted as:

- Of importance

$\bullet$ Of major importance

1. Tian DH, Wan B, Bannon PG, Misfeld M, LeMaire SA, Kazui T, et al. A meta-analysis of deep hypothermic circulatory arrest versus moderate hypothermic circulatory arrest with selective antegrade cerebral perfusion. Ann Cardiothorac Surg. 2013;2:14858. https://doi.org/10.3978/j.issn.2225-319X.2013.03.13.

2. Caplan LR, Hennerici M. Impaired clearance of emboli (washout) is an important link between hypoperfusion, embolism and ischemic stroke. Arch Neurol. 1998;55:1475-82. https://doi.org/ 10.1001/archneur.55.11.1475.

3. Doblar DD. Intraoperative transcranial ultrasonic monitoring for cardiac and vascular surgery. Semin Cardiothorac Vasc Anesth. 2004;8:127-45. https://doi.org/10.1177/108925320400800206.

4. Blauth CI. Macroemboli and microemboli during cardiopulmonary bypass. Ann Thorac Surg. 1995;59:1300-3. https://doi.org/ 10.1016/0003-4975(95)00105-t.

5. Borger MA, Peniston CM, Weisel RD, et al. Neuropsychologic impairment after coronary bypass surgery: effect of gaseous microemboli during perfusionist interventions. J Thorac Cardiovasc Surg. 2001;121:743-9. https://doi.org/10.1067/mtc.2001. 112526.

6. Hori D, Nomura Y, Ono M, Joshi B, Mandal K, Cameron D, et al. Optimal blood pressure during cardiopulmonary bypass defined by cerebral autoregulation monitoring. J Thorac Cardiovasc Surg. 2017;154:1590-8.e2. https://doi.org/10.1016/j.jtcvs. 2017.04.091.

7. Lewis C, Parulkar SD, Bebawy J, Sherwani S, Hogue CW. Cerebral neuromonitoring during cardiac surgery: a critical appraisal with an emphasis on near-infrared spectroscopy. J Cardiothorac Vasc Anesth. 2018;32:2313-22. https://doi.org/10.1053/j.jvca. 2018.03.032.

8. Aaslid R, Markwalder T-M, Nornes H. Noninvasive transcranial Doppler ultrasound recording of flow velocity in basal cerebral arteries. J Neurosurg. 1982;57(6):769-74. https://doi. org/10.3171/jns.1982.57.6.0769.

9. Lam JM, Smielewski P, Czosnyka M, Pickard JD, Kirkpatrick PJ. Predicting delayed ischemic deficits after aneurysmal subarachnoid hemorrhage using a transient hyperemic response test of cerebral autoregulation. Neurosurgery. 2000;47:819-25. https://doi.org/10.1097/00006123-200010000-00004.

10. Czosnyka M, Balestreri M, Steiner L, Smielewski P, Hutchinson PJ, Matta B, et al. Age, intracranial pressure, autoregulation, and outcome after brain trauma. J Neurosurg. 2005;102:450-4. https://doi.org/10.3171/jns.2005.102.3.0450.

11. Varsos GV, Kasprowicz M, Smielewski P, Czosnyka M. Model-based indices describing cerebrovascular dynamics. 
Neurocrit Care. 2014;20:142-57. https://doi.org/10.1007/ s12028-013-9868-4.

12••. Roach GW, Kanchuger M, Mangano CM, Newman M, Nussmeier N, Wolman R, et al. Adverse cerebral outcomes after coronary bypass surgery. Multicenter Study of Perioperative Ischemia Research Group and the Ischemia Research and Education Foundation Investigators. N Engl J Med. 1996;335:1857-63. https://doi.org/10.1056/NEJM199612 193352501 Prospective multicenter study from 24 US institutions for two general categories of neurologic outcomes: stroke, stupor, or coma at discharge, and deterioration in intellectual function, memory, deficit, or seizures.

13. Purkayastha S, Sorond F. Transcranial Doppler ultrasound: technique and application. Sem Neurol. 2012;32:411-20. https://doi.org/10.1055/s-0032-1331812.

14. Razumovsky AY, Gugino LD, Owen JH. Advanced neurologic monitoring for cardiac surgery. Curr Cardiol Rep. 2006;8:1722. https://doi.org/10.1007/s11886-006-0005-2.

15. Saidi N, Murkin JM. Applied neuromonitoring in cardiac surgery: patient specific management. Semin Cardiothorac Vasc Anesth. 2005;9:17-23. https://doi.org/10.1177/1089253205 00900103.

16. Brillman J. Detection of microemboli from the heart. In: Babikian VL, Wechsler LR, editors. Transcranial Doppler ultrasonography. Boston: Butterworth-Heinemann; 1999. p. $175-8$.

17. Stump DA, Kashemi DR. Neurologic outcome of monitoring during cardiac surgery. In: Babikian VL, Wechsler LR, editors. Transcranial Doppler ultrasonography. Boston: ButterworthHeinemann; 1999.

18. Ackerstaff RG, Moons KG, van der Vlasakker CJ, Moll FL, Vermeulen FE, Algra A, et al. Association of intraoperative transcranial Doppler monitoring variables with stroke from carotid endarterectomy. Stroke. 2000;31:1817-23. https://doi. org/10.1161/01.str.31.8.1817.

19. Caplan LR. Protecting the brains of patients after heart surgery. Arch Neurol. 2001;58:549-50. https://doi.org/10.1001/ archneur.58.4.549.

20. Newman MF, Grocott HP, Mathew JP, White WD, Landolfo K, Reves JG, et al. Report of the substudy assessing the impact of neurocognitive function on quality of life 5 years after cardiac surgery. Stroke. 2001;32:2874-81. https://doi.org/10.1161/ hs 1201.099803.

21. Selnes OA, Royall RM, Grega MA, Borowicz LM Jr, Quaskey S, McKhann GM. Cognitive changes 5 years after coronary artery bypass grafting: is there evidence of late decline? Arch Neurol. 2001;58:598-604. https://doi.org/10.1001/archneur. 58.4.598

22. Mark DB, Newman MF. Protecting the brain in coronary artery bypass graft surgery. JAMA. 2002;287:1448-50. https://doi.org/ 10.1001/jama.287.11.1448.

23. Mitchell SJ, Merry AF. Perspective on cerebral microemboli in cardiac surgery: significant problem or much ado about nothing? J Extra Corpor Technol. 2015;47:10-5.

24. Barbut D, Lo YW, Hartman GS, Yao FS, Trifiletti RR, Hager $\mathrm{DN}$, et al. Aortic atheroma is related to outcome but not numbers of emboli during coronary bypass. Ann Thorac Surg. 1997;64:454-9. https://doi.org/10.1016/S0003-4975(97) 00523-7.

25. Barbut D, Grassineau D, Heier L, Lis E, Hartmann G, Isom OW. Posterior distribution of infarcts in strokes related to cardiac operations. Ann Thorac Surg. 1998;65:1656-9. https://doi.org/ 10.1016/s0003-4975(98)00272-0.

26. Uretsky G, Landsburg G, Cohn D, Wax Y, Borman JB. Analysis of microembolic particles originating in extracorporeal circuits. Perfusion. 1987;2:9-17.
27. Blauth CI, Arnold JV, Schulenberg WE, McCartney AC, Taylor KM, Loop FD. Cerebral microembolism during cardiopulmonary bypass: retinal microvascular studies in vivo with fluorescein angiography. J Thorac Cardiovasc Surg. 1988;95:668-76.

28. Ionescu MI, Wooler GH. Current techniques in extracorporeal circulation. London. Boston: Butterworths; 1976.

29. Brooker RF, Brown WR, Moody DM, Hammon JW Jr, Reboussin DM, Deal DD, et al. Cardiotomy suction: a major source of brain lipid emboli during cardiopulmonary bypass. Ann Thorac Surg. 1998;65:1651-5. https://doi.org/10.1016/s0003-4975(98) 00289-6.

30•. Patel N, Minhas JS, Chung EM. Intraoperative embolization and cognitive decline after cardiac surgery: a systematic review. Semin Cardiothorac Vasc Anesth. 2016;20:225-31. https:// doi.org/10.1177/1089253215626728 An important systemic review reporting that the current literature is indecisive whether the embolization during cardiac surgery has any adverse impact on cognition.

31. Francis TJR, Mitchell SJ. Pathophysiology of decompression sickness. In: Brubakk AO, Neuman TS. Bennett and Elliott's physiology and medicine of diving, 5th ed. Philadelphia: Saunders Ltd.; 2003.

32. Barak M, Katz Y. Microbubbles: pathophysiology and clinical implications. Chest. 2005;128:2918-32. https://doi.org/10.1378/ chest.128.4.2918.

33. Chryssanthou C, Springer M, Lipschitz. Blood-brain and bloodlung barrier alteration by dysbaric exposure. Undersea Biomed Res. 1977;4:117-29.

34. Chryssanthou C, Graber B, Mendelson S, Goldstein G. Increased blood brain barrier permeability to tetracycline in rabbits under dysbaric conditions. Undersea Biomed Res. 1979;6:319-28.

35. Nohara A, Yusa T. Reversibility in blood-brain barrier, microcirculation, and histology in rat brain after decompression. Undersea Hyperb Med. 1997;24:15-21.

36. Jabur GNS, Willcox TW, Zahidani S, Sidhu K, Mitchell SJ Reduced embolic load during clinical cardiopulmonary bypass using a 20 micron arterial filter. Perfusion. 2014;29:219-25. https://doi.org/10.1177/0267659113504445.

37. Gerriets T, Schwarz N, Bachmann G, Kaps M, Kloevekorn WP, Sammer G, et al. Evaluation of methods to predict early longterm neurobehavioral outcome after coronary artery bypass grafting. Am J Cardiol. 2010;105:1095-101. https://doi.org/10. 1016/j.amjcard.2009.12.009.

38. Wang X, Ji B, Yang B, Liu G, Miao N, Yang J, et al. Real-time continuous neuromonitoring combines transcranial cerebral Doppler with near-infrared spectroscopy cerebral oxygen saturation during total aortic arch replacement procedure: a pilot study. ASAIO J. 2012;58:122-6. https://doi.org/10.1097/MAT. 0b013e318241abd3.

39. Catena E, Tasca G, Fracasso G, Toscano A, Bonacina M, Narang T, et al. Usefulness of transcranial color Doppler ultrasonography in aortic arch surgery. J Cardiovasc Med. 2013;14:597-602. https://doi.org/10.2459/JCM.0b013e3283 $56 \mathrm{a} 485$.

40. Ghazy T, Darwisch A, Schmidt T, Fajfrova Z, Zickmüller C, Masshour A, et al. Transcranial Doppler sonography for optimization of cerebral perfusion in aortic arch operation. Ann Thorac Surg. 2016;101:e15-6. https://doi.org/10.1016/j.athor acsur.2015.06.055.

41. Ghazy T, Darwisch A, Schmidt T, Nguyen P, Elmihy S, Fajfrova $Z$, et al. The transcranial Doppler sonography for optimal monitoring and optimization of cerebral perfusion in aortic arch surgery: a case series. Heart Surg Forum. 2017;20:E0858. https://doi.org/10.1532/hsf.1755. 
42. Gorman M. Transcranial Doppler assessment of cerebral embolic disorders. Prog Cardiovasc Dis. 2000;43:135-50. https://doi.org/10.1053/pcad.2000.9028.

43. Borger MA, Feindel CM. Cerebral emboli during cardiopulmonary bypass: effect of perfusionist interventions and aortic cannulas. J Extra Corpor Technol. 2002;34:29-33.

44. Murkin JM. Applied neuromonitoring and improving CNS outcomes. Semin Cardiothorac Vasc Anesth. 2005;9:139-42. https://doi.org/10.1177/108925320500900206.

45. Nötzold A, Khattab AA, Eggers J. Microemboli in aortic valve replacement. Expert Rev Cardiovasc Ther. 2006;4:853-9. https://doi.org/10.1586/14779072.4.6.853.

46. Rodriguez RA, Ruel M, Labrosse M, Mesana T. Transcranial Doppler and acoustic pressure fluctuations for the assessment of cavitation and thromboembolism in patients with mechanical heart valves. Interact Cardiovasc Thorac Surg. 2008;7:17983. https://doi.org/10.1510/icvts.2007.167569.

47. Martin KK, Wigginton JB, Babikian VL, Pochay VE, Crittenden MD, Rudolph JL. Intraoperative cerebral high-intensity transient signals and postoperative cognitive function: a systematic review. Am J Surg. 2009;197:55-63. https://doi.org/ 10.1016/j.amjsurg.2007.12.060.

48. Fedorow C, Grocott HP. Cerebral monitoring to optimize outcomes after cardiac surgery. Curr Opin Anaesthesiol. 2010;23:89-94. https://doi.org/10.1097/ACO.0b013e3283 $346 \mathrm{~d} 10$.

49. Kruis RW, Vlasveld FA, Van Dijk D. The (un)importance of cerebral microemboli. Semin Cardiothorac Vasc Anesth. 2010;14:111-8. https://doi.org/10.1177/1089253210370903.

50. Lou S, Ji B, Liu J, Yu K, Long C. Generation, detection and prevention of gaseous microemboli during cardiopulmonary bypass procedure. Int J Artif Organs. 2011;34:1039-51. https://doi.org/10.5301/ijao.5000010.

51•. Rodriguez RA, Nathan HJ, Ruel M, Rubens F, Dafoe D, Mesana T. A method to distinguish between gaseous and solid cerebral emboli in patients with prosthetic heart valves. Eur J Cardiothorac Surg. 2009;35:89-95. https://doi.org/10.1016/j. ejcts.2008.09.020 An observational study demonstrating a potentially reliable method to distinguish non-gaseous from gaseous emboli.

52•. Abu-Omar Y, Balacumaraswami L, Pigott DW, Matthews PM, Taggart DP. Solid and gaseous cerebral microembolization during off-pump, on-pump, and open cardiac surgery procedures. J Thorac Cardiovasc Surg, Prospective study demonstrating that cerebral microembolization is significantly reduced with avoidance of cardiopulmonary bypass. 2004;127:1759-65. https://doi.org/10.1016/j.jtcvs.2003.09. 048 .

53. Diegeler A, Hirsch R, Schneider F, Schilling LO, Falk V, Rauch $\mathrm{T}$, et al. Neuromonitoring and neurocognitive outcome in offpump versus conventional coronary bypass operation. Ann Thorac Surg. 2000;69:1162-6. https://doi.org/10.1016/s00034975(99)01574-x.

54. Zamvar V, Williams D, Hall J, Payne N, Cann C, Young K, et al. Assessment of neurocognitive impairment after off-pump and on-pump techniques for coronary artery bypass graft surgery: prospective randomised controlled trial. BMJ. 2002;325:1268. https://doi.org/10.1136/bmj.325.7375.1268.

55. Van Dijk D, Jansen EW, Hijman R, Nierich AP, Diephuis JC, Moons KG, et al. Cognitive outcome after off-pump and onpump coronary artery bypass graft surgery: a randomized trial. JAMA. 2002;287:1405-12. https://doi.org/10.1001/jama.287.11. 1405.

56. Van Dijk D, Spoor M, Hijman R, Nathoe HM, Borst C, Jansen EW, et al. Cognitive and cardiac outcomes 5 years after off-pump vs on-pump coronary artery bypass graft surgery. JAMA. 2007;297:701-8. https://doi.org/10.1001/jama.297.7.701.

57. Neville MJ, Butterworth J, James RL, Hammon JW, Stump DA. Similar neurobehavioral outcome after valve or coronary artery operations despite differing carotid embolic counts. J Thorac Cardiovasc Surg. 2001;121:125-36. https://doi.org/10.1067/mtc. 2001.111378.

58. Dekluder G, Lecroart JL, Savoye C, Coquet B, Houdas Y. Transcranial high-intensity Doppler signals in patients with mechanical heart valve prostheses: their relationship with abnormal intracavitary echoes. J Heart Valve Dis. 1996;5:662-7.

59. Johansen P. Mechanical heart valve captivation. Expert Rev Med Devices. 2004;1:95-104. https://doi.org/10.1586/17434440.1.1. 95.

60. Geiser T, Sturzenegger M, Genewein U, Haeberli A, Beer JH. Mechanisms of cerebrovascular events as assessed by procoagulant activity, cerebral microemboli, and platelet microparticles in patients with prosthetic heart valves. Stroke. 1998;29:1770-7. https://doi.org/10.1161/01.str.29.9.1770.

61. Dexter EU, Aluri S, Radcliffe RR, Zhu H, Carlson DD, Heilman TE, et al. In vivo demonstration of cavitation potential of a mechanical heart valve. ASAIO J. 1999;45:436-41. https://doi. org/10.1097/00002480-199909000-00014.

62. Newman MF, Kirchner JL, Phillips-Bute B, Gaver V, Grocott $\mathrm{H}$, Jones RH, et al. Longitudinal assessment of neurocognitive function after coronary-artery bypass surgery. N Engl J Med. 2001;344:395-402. https://doi.org/10.1056/NEJM20010208344 0601.

63. Montague NT 3rd, Kouchoukos NT, Wilson TA, Bennett AL 3rd, Knott HW, Lochridge SK, et al. Morbidity and mortality of coronary bypass grafting in patients 70 years of age and older. Ann Thorac Surg. 1985;39:552-7. https://doi.org/10.1016/ s0003-4975(10)61997-2.

64. Kirsch M, Guesnier L, LeBesnerias P, Hillion ML, Debauchez $\mathrm{M}$, Seguin J, et al. Cardiac operations in octogenarians: perioperative risk factors for death and impaired autonomy. Ann Thorac Surg. 1998;66:60-7. https://doi.org/10.1016/s0003-4975(98) 00360-9.

65. Qu JZ, Kao LW, Smith JE, Kuo A, Xue A, Iyer MH, et al. Brain protection in aortic arch surgery: an evolving field. J Cardiothorac Vasc Anesth. 2021;35:1176-88. https://doi.org/10.1053/j. jvca.2020.11.035.

66. Moritz S, Kasprzak P, Arlt M, Taeger K, Metz C. Accuracy of cerebral monitoring in detecting cerebral ischemia during carotid endarterectomy: a comparison of transcranial Doppler sonography, near-infrared spectroscopy, stump pressure, and somatosensory evoked potentials. Anesthesiology. 2007;107:563-9. https:// doi.org/10.1097/01.anes.0000281894.69422.ff.

67. Steiner LA, Coles JP, Johnston AJ, Chatfield DA, Smielewski P, Fryer TD, et al. Assessment of cerebrovascular autoregulation in head-injured patients: a validation study. Stroke. 2003;34:24049. https://doi.org/10.1161/01.STR.0000089014.59668.04.

68. Minhas PS, Smielewski P, Kirkpatrick PJ, Pickard JD, Czosnyka M. Pressure autoregulation and positron emission tomographyderived cerebral blood flow acetazolamide reactivity in patients with carotid artery stenosis. Neurosurgery. 2004;55:63-7. https://doi.org/10.1227/01.neu.0000126876.10254.05.

69. Czosnyka M, Brady K, Reinhard M, Smielewski P, Steiner LA. Monitoring of cerebrovascular autoregulation: facts, myths, and missing links. Neurocrit Care. 2009;10:373-86. https://doi.org/ 10.1007/s12028-008-9175-7.

70. Kampf S, Schramm P, Klein KU. Transcranial Doppler and near infrared spectroscopy in the perioperative period. Curr Opin Anaesthesiol. 2013;26:543-8. https://doi.org/10.1097/01.aco. 0000432517.70844.a6. 
71. Guarracino F. Cerebral monitoring during cardiovascular surgery. Curr Opin Anaesthesiol. 2008;21:50-4. https://doi.org/10. 1097/ACO.0b013e3282f3f499.

72. Alexandrov AV, Sloan MA, Tegeler $\mathrm{CH}$, et al. Practice standards for transcranial Doppler (TCD) ultrasound. Part II. Clinical indications and expected outcomes. J Neuroimaging. 2012;22:21524. https://doi.org/10.1111/j.1552-6569.2010.00523.x.

73. Baufreton C, Pinaud F, Corbeau JJ, Chevailler A, Jolivot D, Ter Minassian A, et al. Increased cerebral blood flow velocities assessed by transcranial Doppler examination is associated with complement activation after cardiopulmonary bypass. Perfusion. 2011;26:91-8. https://doi.org/10.1177/0267659110392439.

74••. Hogue CW, Brown CH 4th, Hori D, Ono M, Nomura Y, Balmert LC, et al. Personalized blood pressure management during cardiac surgery with cerebral autoregulation monitoring: a randomized trial. Semin Thorac Cardiovasc Surg. 2021;33:429-38. https://doi.org/10.1053/j.semtcvs.2020.09.032 A randomized trial showing that a MAP-based cerebral autoregulation target did not reduce the frequency of stroke or delayed neurological recovery but associated with reduced risk of delirium and improved memory.
75. Halsey JH, McDowell HA, Gelmon S, et al. Blood velocity in the middle cerebral artery and regional cerebral blood flow during carotid endarterectomy. Stroke. 1989;20:53-8. https://doi.org/ 10.1161/01.str.20.1.53.

76. Erdoes G, Basciani R, Huber C, Stortecky S, Wenaweser P, Windecker S, et al. Transcranial Doppler-detected cerebral embolic load during transcatheter aortic valve implantation. Eur J Cardiothorac Surg. 2012;41:778-83. https://doi.org/10.1093/ejcts/ ezr068.

77. Webb JG, Barbanti M. Cerebral embolization during transcatheter aortic valve implantation. Circulation. 2012;126:1567-9. https://doi.org/10.1161/CIRCULATIONAHA.112.136796.

Publisher's Note Springer Nature remains neutral with regard to jurisdictional claims in published maps and institutional affiliations. 